\title{
Lignin pyrolysis reactions
}

\author{
Haruo Kawamoto ${ }^{1}$
}

Received: 2 November 2016 / Accepted: 17 December 2016 / Published online: 17 January 2017

(C) The Author(s) 2017. This article is published with open access at Springerlink.com

\begin{abstract}
Lignin, an aromatic constituent of woody biomass, is a potential renewable aromatic feedstock for a sustainable future carbon economy. Pyrolysis-based technologies, such as fast pyrolysis and gasification, are promising methods for converting lignin into biochemicals, biomaterials, and biofuels. A better understanding of the molecular mechanisms involved in lignin pyrolysis/gasification would guide the development of the controlled pyrolysis and gasification systems to overcome issues with low product selectivity, an intrinsic drawback of current pyrolysis-based technologies. This review article summaries the state-ofthe-art research into molecular mechanisms of lignin pyrolysis and gasification. This information should also be useful for understanding the influence of high temperature heat treatments on the properties of wood.
\end{abstract}

Keywords Lignin - Pyrolysis - Molecular mechanism · Homolysis $\cdot$ Heterolysis

\section{Introduction}

Many renewable energy options are available including photovoltaic, wind, and geothermal electricity generation. However, biomass resources are the only renewable source of carbon for use in chemicals and materials. Large amounts of the earth's biomass resources are accumulated in forest

Publishing and availability of open access articles were supported by JSPS KAKENHI Grant Number JP16HP2001.

Haruo Kawamoto

kawamoto@energy.kyoto-u.ac.jp

1 Graduate School of Energy Science, Kyoto University, Yoshida-honmachi, Sakyo-ku, Kyoto 606-8501, Japan ecosystems, with an annual turnover of approximately $6 \%$ through photosynthesis [1]. Lignin, which accounts for $20-35 \%$ of wood (by weight), is an important renewable aromatic feedstock along with cellulose and hemicellulose, the polysaccharide components. Thus, it is important to establish efficient lignin utilization technologies.

Pyrolysis is defined as thermal degradation under a limited amount of oxygen and pyrolysis-based technologies show great promise for converting lignin and other wood components into biochemicals, biomaterials, and biofuels. For example, fast pyrolysis of wood, with a short residence time for volatile intermediates in the heating zone, produces good yields of an organic liquid that contains useful lignin-derived aromatic chemicals, which may then be separated $[2,3]$. However, due to the low product selectivity, the necessary separation processes are tedious and costly, which limits the practical use of pyrolysis methods. Gasification provides an option to produce synthetic petroleum from wood via the conversion of syngas $\left(\mathrm{CO}\right.$ and $\left.\mathrm{H}_{2}\right)$ on Fischer-Tropsch catalysts. However, problems arising from the formation of tar and coke (solid carbonized substances converted from tar) are major drawbacks for establishing reliable wood gasification systems [4-6]. These substances cause pipeline clogging, catalyst deactivation and other issues. Lignin is considered to produce aromatic tar and coke during gasification. A better understanding of the molecular mechanisms involved in wood pyrolysis and gasification may guide the development of more efficient and reliable systems by addressing the aforementioned drawbacks.

Although it is not easy to define classes of pyrolysis and gasification reactions, such reactions may be generally divided into two stages, i.e., primary pyrolysis and secondary pyrolysis reactions [7]. Wood constituent polymers decompose into volatile and char (solid carbonized 
material) intermediates in the primary pyrolysis stage, which are then degraded further in the secondary pyrolysis reaction stage. Accordingly, this review article also follows this classification.

\section{Effect of temperature on pyrolysis products}

Lignin is a polymer of phenylpropane units containing three different aromatic ring substitution patterns: $p$-hydroxyphenyl $(\mathrm{H})$, guaiacyl (4-hydroxy-3-methoxyphenyl, $\mathrm{G}$ ) and syringyl (3,5-dimethoxy-4-hydroxyphenyl, S) depending on the wood species [8]. Softwoods contain a greater proportion of $\mathrm{G}$ units and smaller amounts of the $\mathrm{H}$ units, whereas hardwoods consist of mainly $\mathrm{G}$ and $\mathrm{S}$ units. These monomers are linked together through various kinds of ether linkages $(\mathrm{C}-\mathrm{O})$ and condensed $(\mathrm{C}-\mathrm{C})$ bonds, which leads to a heterogeneous chemical structure for lignins. Owing to these heterogeneous features, the behavior of lignins during pyrolysis reactions depends on the pyrolysis temperature. As illustrated in Fig. 1 [9], thermogravimetric (TG) analysis of lignin shows several derivative TG (DTG) peaks at $350^{\circ} \mathrm{C}$ from primary pyrolysis reactions and at $400-450{ }^{\circ} \mathrm{C}$ (methoxyl group-related reactions) and at $550-600^{\circ} \mathrm{C}$ (gasification of catechols (1,2-dihydroxybenzenes)) from secondary pyrolysis reactions. This is in contrast to the pyrolysis of cellulose, a homogeneous polymer of D-glucose units connected via $\beta-1 \rightarrow 4$ linkages, which exhibits only one sharp DTG peak around $350^{\circ} \mathrm{C}$.

The chemical structures of the pyrolysis products of lignins have been evaluated by gas chromatography/mass spectrometry (GC/MS) [10-12], nuclear magnetic resonance (NMR) [12-18] and infrared (IR) spectroscopic [15, 19-21] analyses, along with pyrolysis directly coupled with GC/MS [22-35] and IR [19, 36-39] (Py-GC/MS, Py-IR). Aromatic methoxy groups are stable during the primary pyrolysis stage and become very reactive in the temperature

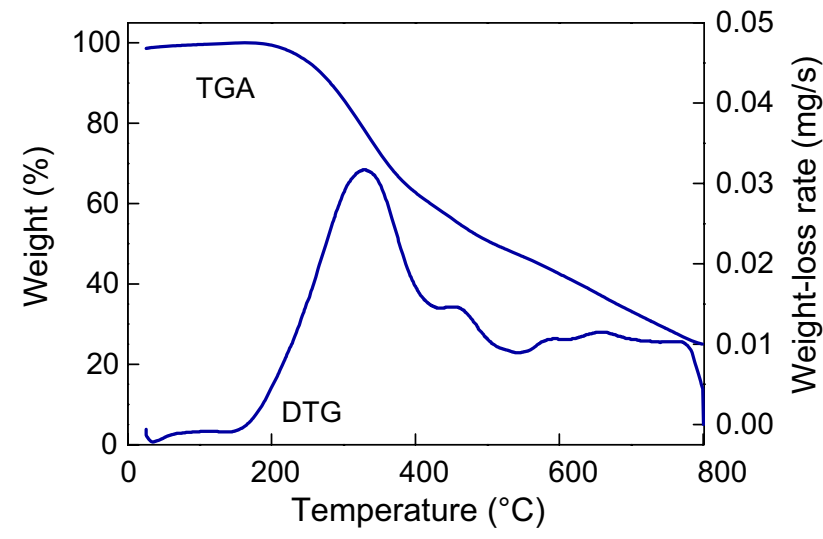

Fig. 1 Thermogravimetric analysis of milled wood lignin isolated from Japanese cedar (Cryptmeria japonica) [9] range of $400-450{ }^{\circ} \mathrm{C}$. Thus, the aromatic compounds produced during the primary pyrolysis stage are predominantly 4-substituted guaiacols (2-methoxyphenols) from G-lignins (Fig. 2) and 4-substituted syringols (2,6-dimethoxyphenols) from $\mathrm{S}$-lignins. The majority of side-chains are unsaturated alkyl groups (i.e., alkyl groups containing $>\mathrm{C}=\mathrm{C}<$, $>\mathrm{C}=\mathrm{O}$ and conjugated $>\mathrm{C}=\mathrm{O}$ bonds) along with a smaller amount of saturated alkyls groups. The major volatile products from G-lignins in this stage include coniferyl alcohol ( $\left.\mathrm{R}:-\mathrm{CH}=\mathrm{CH}-\mathrm{CH}_{2} \mathrm{OH}\right)$, coniferyl aldehyde ( $\mathrm{R}:-\mathrm{CH}=\mathrm{CH}-\mathrm{CHO})$, isoeugenol $\left(\mathrm{R}:-\mathrm{CH}=\mathrm{CH}-\mathrm{CH}_{3}\right)$, 4-vinylguaiacol $\left(\mathrm{R}:-\mathrm{CH}=\mathrm{CH}_{2}\right)$, vanillin $(\mathrm{R}:-\mathrm{CHO})$, acetovanillone $\left(\mathrm{R}:-\mathrm{CO}-\mathrm{CH}_{3}\right)$, and dihydroconiferyl alcohol (R: $-\mathrm{CH}_{2}-\mathrm{CH}_{2}-\mathrm{CH}_{2} \mathrm{OH}$ ).

When the pyrolysis temperature is increased to $400-450{ }^{\circ} \mathrm{C}$, secondary pyrolysis reactions take place and guaiacols/syringols rapidly transition to catechols (2-hydroxyphenols)/pyrogallols (2,3-dihydroxyphenols) and $o$-cresols (2-methylphenols)/xylenols (dimethylphenols) along with phenols (Fig. 2). In this temperature range, cracking of side-chain $\mathrm{C}-\mathrm{C}$ bonds occurs, which increases the yields of monomers. The reaction products transition from unsaturated to saturated alkyls side chains (methyl, ethyl, propyl, 3-hydroxypropyl and others) and non-substituted $(-\mathrm{H})$ types. Coke and polycyclic aromatic hydrocarbons (PAHs) formation also starts. Around $550^{\circ} \mathrm{C}$, catechols and pyrogallols disappear and non-condensable gas yields (particularly $\mathrm{CO}$ ) significantly increase. At temperatures $>700{ }^{\circ} \mathrm{C}$ the formation of PAHs is enhanced. Phenols and $o$-cresols are relatively stable at such high temperatures; hence, these compounds are observed along with PAHs even during high-temperature pyrolysis.

\section{Primary pyrolysis reactions $\left(200-400^{\circ} \mathrm{C}\right)$}

Primary pyrolysis reactions of lignins occur over a wide temperature range of $200-400^{\circ} \mathrm{C}$ with a DTG peak around $350^{\circ} \mathrm{C}$. As noted, lignins are heterogeneous polymers that arise from the inclusion of various types of linkages between phenylpropane units. As an example, spruce (a softwood) milled wood lignin (MWL) is reported to include $63-67 \%$ ether linkages (including $48 \% \beta$-ether and $11.5-15 \% \alpha$-ether linkages) and 30-35\% condensed linkages (including 9.5-11\% 5-5' (biphenyl) and 9-12\% $\beta$-aryl] [8]. The proportions of ether linkages in hardwood lignins are normally higher than those of the softwood lignins, as can be seen from the $60 \% \beta$-ether linkage proportion in birch (a hardwood) MWL [8]. Accordingly, the roles of these linkages during pyrolysis are important for understanding the primary pyrolysis reactions of lignins.

The use of model dimers that represent lignin ether and condensed type linkages is an effective means for 
Fig. 2 Effect of pyrolysis temperature on aromatic substitution pattern and side-chain structure of the products from G-type lignin

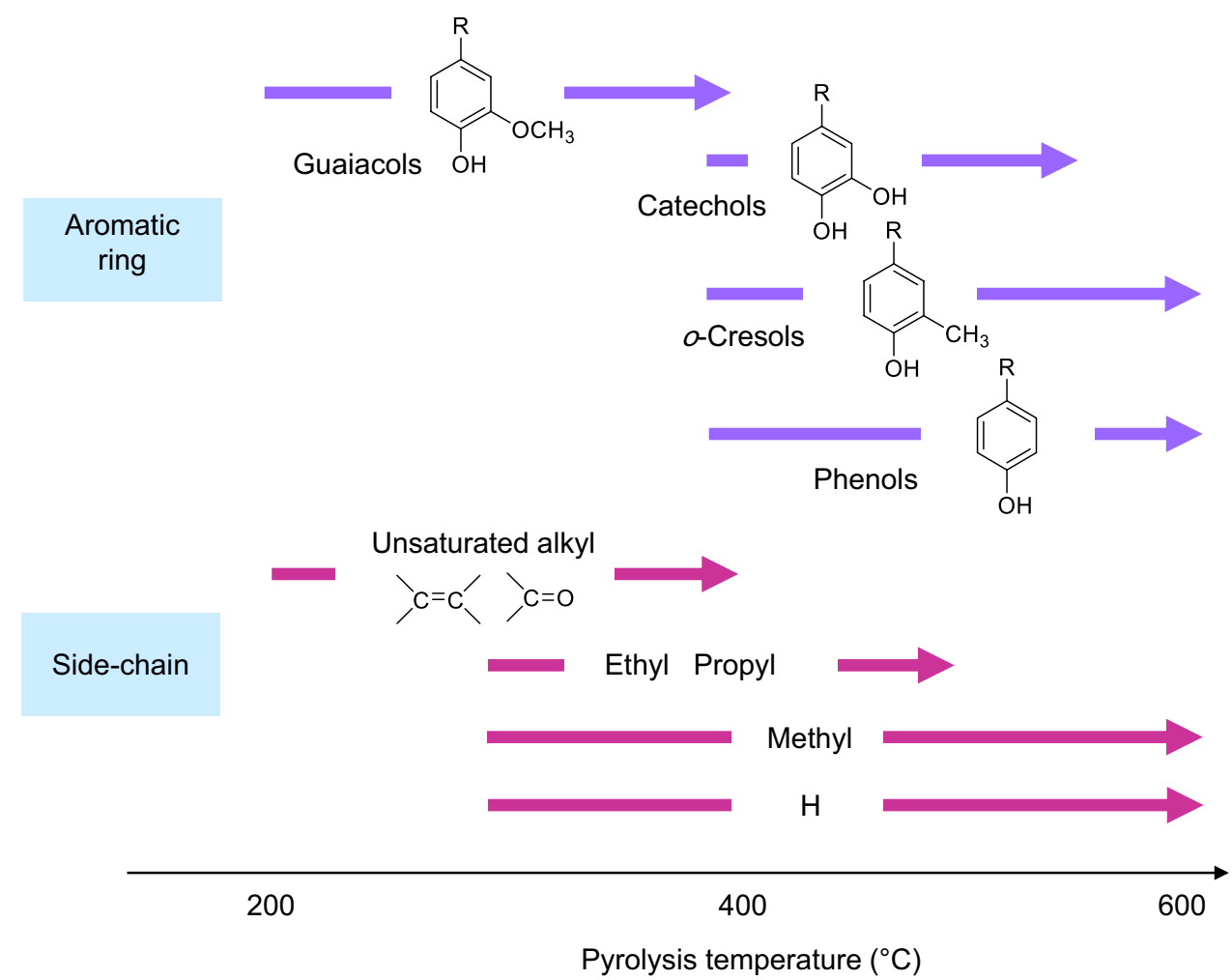

understanding the pyrolytic reactions of lignins. Hence, various model dimers including $\beta$-ether $[20,27,28,34$, $40-53], \alpha$-ether [20, 30, 34, 45, 47, 49, 51, 54], $\beta$-aryl [20, $31,32,47,54], \beta-\beta$ [33], and biphenyl [20, 47, 54] types, trimers $[34,49,51]$ and oligomers/polymers such as dehydrogenative polymerization products of cinnamyl alcohols [35] and $\beta$-ether type polymers [55-57] have been used in pyrolysis studies. Phenolic $(\mathrm{Ph})$ and non-phenolic (Non- $\mathrm{Ph})$ model compounds are commonly used to represent the ends and repeating units of lignin macromolecules, respectively.

Early studies conducted by the Domburg group [54, 58] reported the thermal stability of various model compounds, which were representative of the linkages between phenylpropane-units and side-chains. Analyses of the pyrolysis products of dimers along with NMR analysis of the pyrolyzed lignins revealed that $\alpha$ - and $\beta$-ether bonds are readily cleaved during the primary pyrolysis stage; however, condensed $(\mathrm{C}-\mathrm{C})$ type linkages are stable during depolymerization of lignin macromolecules [13, 20, 47]. The $\mathrm{Ph} \beta$-aryl type dimers give stilbenes selectively, but this reaction does not lead to depolymerization of lignins [20, 47]. Normally, $\mathrm{Ph}$ dimers are more reactive than corresponding Non- $\mathrm{Ph}$ ones [20, 40, 41, 47, 49, 53]. Compared with hardwood lignins, softwood lignins contain a greater proportion of condensed type linkages. Thus, the differences in reactivity of these components can explain the observation that pyrolysis of softwood lignins tend to generate larger amounts of residue than hardwood lignins $[59,60]$.

\section{Bond dissociation energy}

Homolysis of $\mathrm{C}-\mathrm{C}$ and $\mathrm{C}-\mathrm{O}$ bonds to form a pair of radicals is one possible reaction that can explain pyrolytic lignin depolymerization. Recently, many papers have reported theoretical calculations of the bond dissociation energies (BDEs) for linkages in lignin related compounds [61-70]. These include calculations of $\alpha-O-4, \beta-O-4,4-O-$ $5, \beta$-aryl, phenylcoumaran, pinoresinol, dibenzodioxocin type dimers. As summarized in Fig. 3 [63-66, 68, 71], $\alpha-O-4$ type linkages had the weakest bond energies, with BDEs in the range of $40-60 \mathrm{kcal} \mathrm{mol}^{-1}$, while the other bond types exhibited BDEs higher than $60 \mathrm{kcal} \mathrm{mol}^{-1}$. The activation energy $\left(E_{\mathrm{a}}\right)$ for homolysis is considered to be slightly greater than the $\mathrm{BDE}$; thus, the $E_{\mathrm{a}}$ for homolysis of these bonds can be expected to be greater than $60 \mathrm{kcal}$ $\mathrm{mol}^{-1}$, except for the $\alpha-O-4$ type linkages.

Homolysis of the $\mathrm{O}-\mathrm{CH}_{3}$ bonds in lignin aromatic rings can occur by increasing the temperature to around $450{ }^{\circ} \mathrm{C}$ (i.e., the secondary pyrolysis reaction stage). This indicates that $\mathrm{O}-\mathrm{CH}_{3}$ bonds are stable during the primary pyrolysis stage $\left(200-400^{\circ} \mathrm{C}\right)$, which is also supported by results that show the primary pyrolysis products continue to bear their original aromatic methoxy groups. However, the $\mathrm{BDE}$ of the $\mathrm{O}-\mathrm{CH}_{3}$ bond in guaiacol has been measured as $56.3 \mathrm{kcal} \mathrm{mol}^{-1}$ [71], which is lower than the above mentioned BDEs $\left(>60 \mathrm{kcal} \mathrm{mol}^{-1}\right)$. These considerations indicate that direct homolysis of the $\mathrm{C}-\mathrm{O}$ and $\mathrm{C}-\mathrm{C}$ bonds 
<smiles>COc1ccccc1OCCBr</smiles>

$\mathrm{O}-\mathrm{CH}_{3}[71]^{*}$

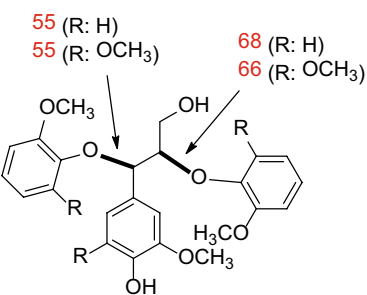

$\alpha-0-4 / \beta-O-4[64]$

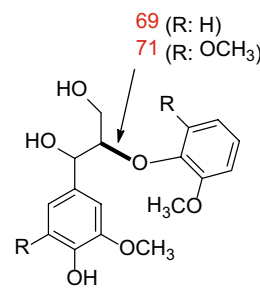

$\beta-0-4$ [64]

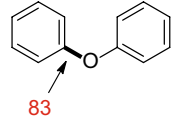

4-O-5 [63]

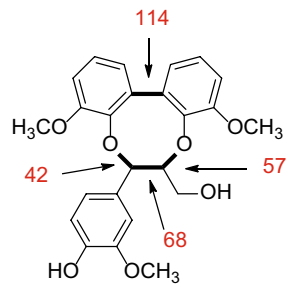

Dibenzodioxocin [66]

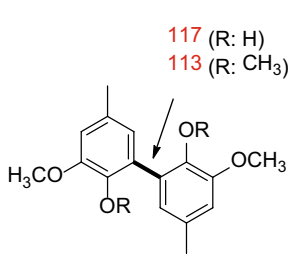

5-5 [64]

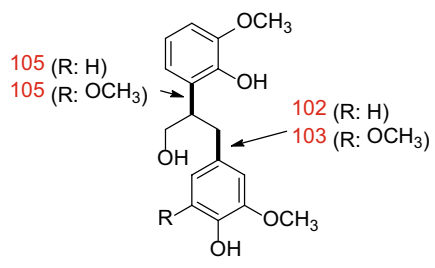

$\beta-5[64]$

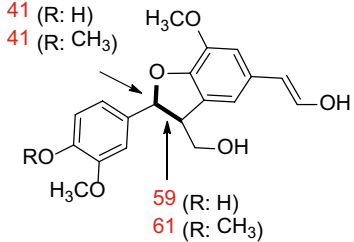

Phenylcoumaran [65]

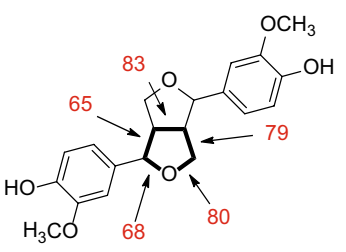

Resinol [68]

Kcal mol-1

* Experimental value

Fig. 3 Bond dissociation energies of various $\mathrm{C}-\mathrm{O}$ and $\mathrm{C}-\mathrm{C}$ bonds in lignin model compounds as evaluated by theoretical calculations

in lignin would not occur during the primary lignin pyrolysis stage except for $\alpha-O-4$ type linkages. Thus, some effects that reduce the cleavage temperatures must be involved in these reactions. Many attempts have been made to model the weight-loss behaviors of lignin during pyrolysis; however, the measured $E_{\mathrm{a}}$ values arise from various pyrolysis reactions, including re-polymerization of the primary products, which reduce the weight-loss rate.

\section{Homolysis and heterolysis mechanisms}

Pyrolytic cleavage of $\mathrm{C}-\mathrm{O}$ and $\mathrm{C}-\mathrm{C}$ bonds can be considered in terms of both homolytic and heterolytic mechanisms, because these mechanisms give the same products as illustrated in Fig. 4 [an example of phenethyl phenyl ether]. The lack of reliable mechanistic evidence has given rise to a long standing controversy concerning which of the homolytic and heterolytic mechanisms take place. Experimental and theoretical investigations have recently been conducted to address this issue.

The theoretical approach provides useful information including $E_{\mathrm{a}}$ for the modelled reactions. Although these $E_{\mathrm{a}}$ values are a useful guide for understanding lignin pyrolysis reactions, a calculated reaction may not occur in reality if other competing reaction pathways with lower energy-barriers are available.

The effects of substituents on the cleavage reactivity provide more direct experimental evidence for a particular

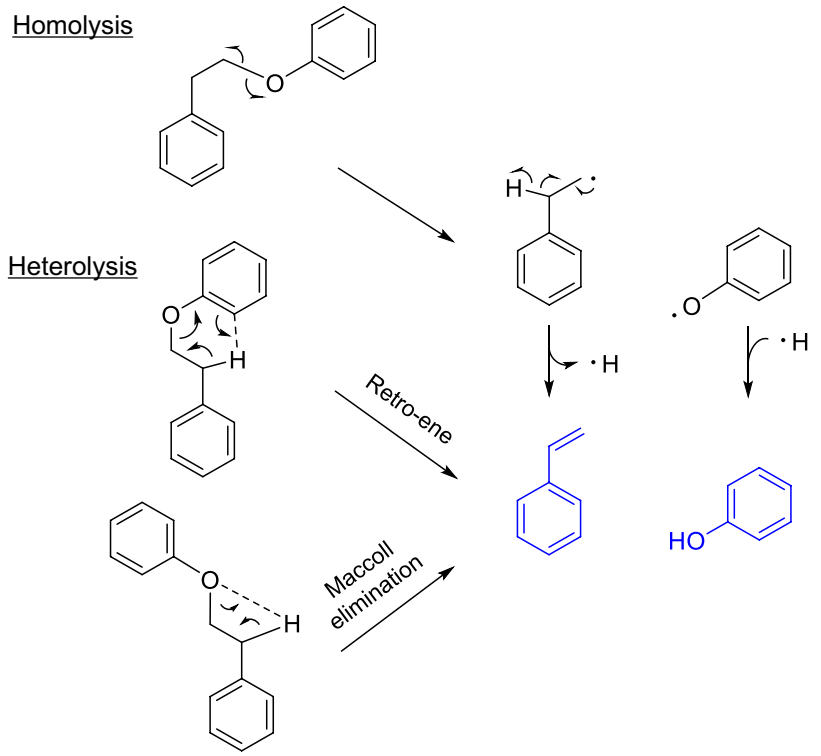

Fig. 4 Homolytic and heterolytic reactions for the conversion of phenethyl phenyl ether into styrene and phenol, as a model of the lignin $\beta$-ether structure

reaction pathway [49]. For example, substituents in the para positions of an aromatic ring have opposing effects on the heterolytic and homolytic cleavage of ether bonds (Fig. 5). Thus, the associated mechanisms are clearly indicated by plots of the cleavage reactivities against a 
Fig. 5 Aromatic substituent effect as a tool for studying homolytic and heterolytic reactions of lignin ether bonds, based on parameters including Hammett $\sigma_{\mathrm{p}}$ and $\triangle \mathrm{BDE}$ (bond dissociation energy)

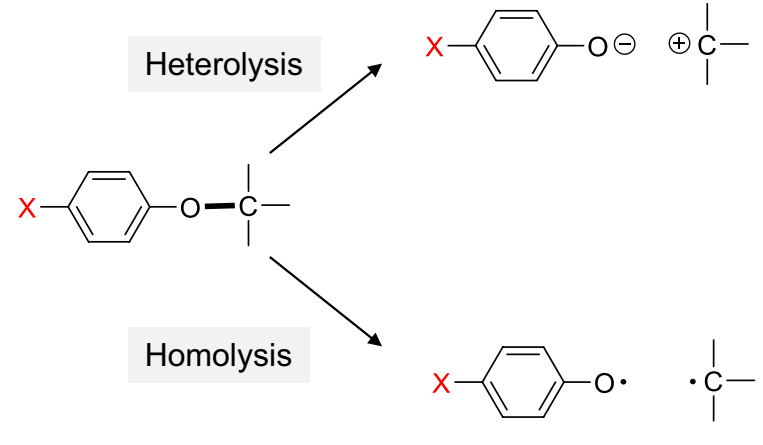

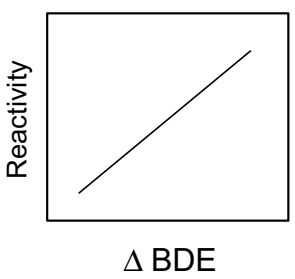

Hammett's substituent constant $\left(\sigma_{p}\right)$ and against the $\triangle \mathrm{BDE}$ (the reduction in the BDE induced by the substituent).

For the heterolytic reaction pathway, the ether linkage is cleaved to form a para substituted phenolate anion. Thus, the reactivity of this pathway should increase as the electron-withdrawing ability of the substituent group increases, stabilizing the anion which results from bond cleavage. This property is quantified as $\sigma_{p}$. Conversely, homolysis of the ether bond forms a phenoxy radical and the reactivity depends on the stability of this species. When a stable radical is formed, cleavage of the ether linkages tends to proceed efficiently, because the increased stability of the radical reduces the $\mathrm{BDE}$ of the aromatic $\mathrm{O}-\mathrm{C}$ bond. The stabilization obtained from substituents is, therefore, reflected in the $\triangle \mathrm{BDE}$ value. When the phenoxy radical is stabilized by electron donating substituents, $\sigma_{p}$ and $\Delta \mathrm{BDE}$ values tend to increase in the opposite order to that of a heterolytic reaction.

\section{Ether cleavage mechanisms}

As discussed above, cleavage of $\alpha$ - and $\beta$-ether bonds plays an important role in lignin depolymerization during the primary pyrolysis stage. Hence, many studies have focused on the pyrolytic cleavage of the $\beta$-ether bond, which is the most abundant linkage type in lignin macromolecules.

Several concerted (heterolytic) mechanisms have been proposed for $\beta$-ether bond cleavage [42, 72-76]. Klein and Virk [42] proposed a six membered retro-ene mechanism based on an analysis of the kinetics for the formation of styrene and phenol from phenethyl phenyl ether. This system is representative of the simplest model compound without any aromatic ring substituents or side chains. In recent theoretical studies Elder and Beste [76] calculated $E_{\text {a }}$ values for retro-ene and Maccoll elimination type concerted mechanisms (Fig. 4), with values of 62-68 kcal mol $\mathrm{l}^{-1}$ and 56-58 $\mathrm{kcal} \mathrm{mol}^{-1}$, respectively. A similar range of values have been reported by other researchers [73-75]. The Nimlos's research group [72] reported the formation of degradation products from the gas-phase pyrolysis of phenethyl phenyl ether and they concluded that the $\mathrm{C}-\mathrm{O}$ homolysis occurred at high temperatures $\left(>1000^{\circ} \mathrm{C}\right)$, whereas the concerted retro-ene and Maccoll mechanisms were significant at lower temperatures $\left(<600^{\circ} \mathrm{C}\right)$.

On the basis of the substituent effects at the para positions of the $\mathrm{C}_{\alpha}$-phenoxyl group (Fig. 5), the $\alpha$-ether bonds in $\mathrm{Ph}$ and Non-Ph (methylated) dimers were confirmed to undergo heterolytic and homolytic cleavage, respectively (Fig. 6A) [49]. These results are consistent with the temperatures required for cleavage of this bond, which vary depending on the presence of $\mathrm{Ph}\left(200^{\circ} \mathrm{C}\right)$ and Non- $\mathrm{Ph}$ $\left(350^{\circ} \mathrm{C}\right)$ type dimers [20]. These results suggested that a push and pull reaction to generate a quinone methide intermediate led to efficient heterolysis of the $\mathrm{C}_{\alpha}-\mathrm{O}$ bond in the $\mathrm{Ph}$ dimer. The low-temperature homolysis of the $\alpha$-ether bond is consistent with the relatively low calculated BDE 40-60 $\mathrm{kcal} \mathrm{mol}^{-1}$, as described above.

Direct homolysis of the $\beta$-ether bond has been clearly indicated from substituent effects on the cleavage reactivities of $\mathrm{Ph}$ and Non- $\mathrm{Ph} \mathrm{C}_{\gamma}$-deoxy type dimers with para substituents for the $\mathrm{C}_{\beta}$-phenoxy group $\left(-\mathrm{H},-\mathrm{OCH}_{3},-\mathrm{Cl}\right)$ as studied in a sealed reactor with tetralin that acts as a hydrogen donor [50]. However, the temperature $\left(400^{\circ} \mathrm{C}\right)$ required to cleave $\beta$-ether bonds in $\mathrm{C}_{\gamma}$-deoxy type dimers could not explain the greater reactivity of guaiacylglycerol$\beta$-guaiacyl ether, a $\mathrm{Ph} \beta$-ether dimer bearing $\mathrm{OH}$ at $\mathrm{C}_{\gamma}$ which has an onset temperature of $250^{\circ} \mathrm{C}$ [20].

The pyrolytic reactivities of $\mathrm{Ph}$ and Non- $\mathrm{Ph} \alpha, \beta$ diether type trimers that include various substituents at the para position of the $\mathrm{C}_{\alpha}$-phenoxy group have provided some insight into the cleavage mechanisms of $\beta$-ether bonds (Fig. 6b, c) [49]. The reactivities of the $\beta$-ether bonds depend solely on those of the $\alpha$-ether bonds, demonstrating that cleavage of the $\alpha$-ether bond acts as the 
Fig. 6 Cleavage mechanisms of lignin ether bonds as suggested by the substituent effects on the reactivities of para substituted model compounds
A

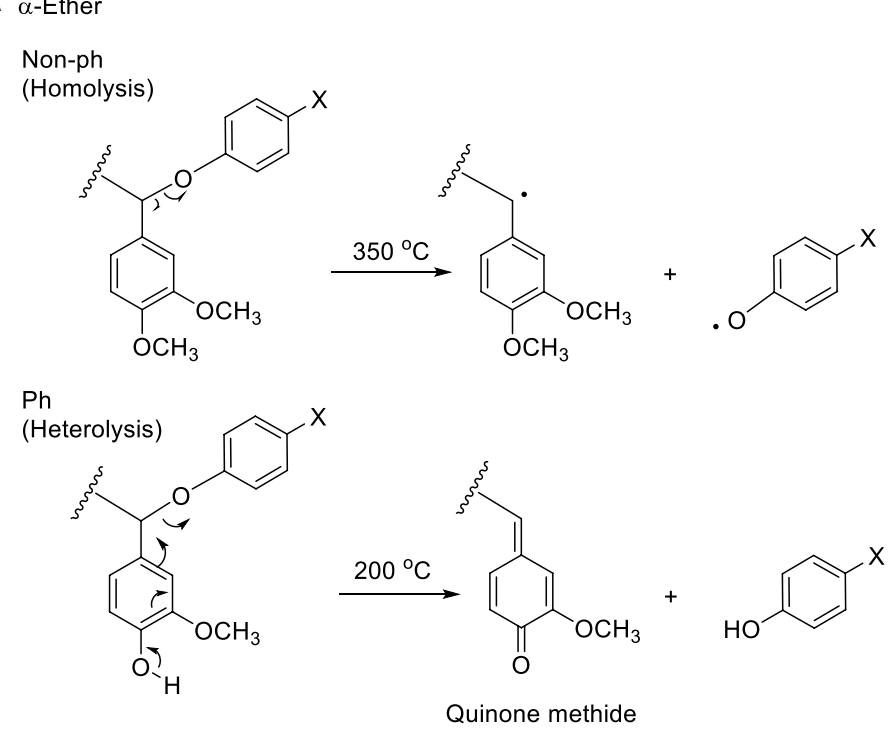

B $\alpha, \beta$-Diether (Non-ph)<smiles>[X]c1ccc(OC(=O)C(C)C(Oc2ccccc2OC)c2ccc(OC)c(OC)c2)cc1</smiles><smiles>COc1ccc(C=C(C)Oc2ccccc2OC)cc1OC</smiles><smiles>C/C=C/c1ccc(OC)c(OC)c1</smiles>

C $\alpha, \beta$-Diether $\mathrm{Ph}$ )

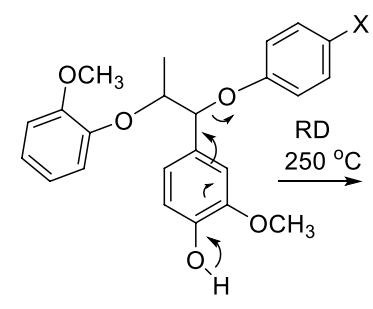<smiles>COC1=CC(=CC(C)Oc2ccccc2OC)C=CC1=O</smiles><smiles>CCCc1ccc(O)c(OC)c1</smiles><smiles>COc1ccccc1OC</smiles>

$\mathrm{RD}$ : rate-determning step rate-determining step. A $\beta$-scission type reaction involving a $\mathrm{C}_{\alpha}$-radical, formed by the homolytic cleavage of the $\mathrm{C}_{\alpha}-\mathrm{O}$ bond, simultaneously cleaves the $\mathrm{C}_{\beta}-\mathrm{O}$ bond homolytically (Fig. 6b). As noted, heterolysis of the $\alpha$-ether bond in $\mathrm{Ph}$ compounds forms a quinone methide intermediate at $200^{\circ} \mathrm{C}$, which results in simultaneous homolytic cleavage of the $\beta$-ether bond in the same temperature range. This result is supported by the observation that the cleavage reactivity is unaffected by the addition of tetralin as a radical scavenger [50], along with the reduced reactivity of the $\mathrm{C}_{\alpha}$-deoxy dimer [45]. Low temperature homolysis of the $\mathrm{C}_{\beta}-\mathrm{O}$ bond, via a quinone methide intermediate, has also been postulated under solvolysis delignification [77-79] and steam-explosion [80] conditions. Ponomarev [81] calculated the $\mathrm{BDE}$ of the $\mathrm{C}_{\beta}-\mathrm{O}$ bond in the quinone methide form to be $44.1 \mathrm{kcal} \mathrm{mol}^{-1}$, a value that is much lower than that of the phenolic form $\left(57.0 \mathrm{kcal} \mathrm{mol}^{-1}\right)$.

The reactivity of guaiacylglycerol- $\beta$-guaiacyl ether is lowered to the level of a Non-Ph dimer by elimination of the hydroxyl group from the $\mathrm{C}_{\gamma}$, [45, 48]. This unexpected result is explained by the missing stabilization effect on the transition state of the quinone methide formation through hydrogen bonding between the $\mathrm{C}_{\alpha}$ and $\mathrm{C}_{\gamma}$ hydroxyl groups. If the quinone methide mechanism occurred effectively during lignin pyrolysis, $\beta$-ether bonds would cleave simultaneously via the newly formed phenolic end groups. However, a careful comparison of the pyrolytic reactivities for model dimers, MWL, and methylated MWLs indicates that 
cleavage of the $\beta$-ether linkages via the quinone methide mechanism does not proceed very efficiently in lignins, likely because of polymeric effects [20].

Radical chain mechanisms have been postulated for the cleavage of lignin $\beta$-ether linkages. The Brit and Beste research group have extensively studied hydrogen abstraction reactions from the $\mathrm{C}_{\alpha}-\mathrm{H}$ bond and subsequent cleavage of the $\beta$-ether bond using phenethyl phenyl ether and its derivatives $[43,44,46]$.

The role of radical chain reactions is clear from the reactivities of the $\mathrm{Ph}$ and Non-Ph $\mathrm{C}_{\gamma}$-deoxy $\beta$-ether dimers, which vary substantially depending on the reactor type, (i.e., open-top and sealed reactors [50]. Although the dimers are recovered without undergoing pyrolysis reactions in open-top reactors, which allows volatile products to exit the heating zone, the reactivities of these compounds are dramatically increased in sealed reactors. Furthermore, the addition of tetralin effectively suppresses the reactivities in sealed reactors. From analysis of the products, two radical chain pathways (Fig. 7) have been suggested, which start from the $\mathrm{C}_{\alpha}$ and phenoxy radicals formed via hydrogen abstraction of $\mathrm{C}_{\alpha}-\mathrm{H}$ and phenolic $\mathrm{OH}$, respectively [51]. These reactions cleave $\beta$-ether bonds to form $\mathrm{C}_{\alpha}=\mathrm{O}$ and $\mathrm{C}_{\alpha}=\mathrm{C}_{\beta}$ type monomers via the $\beta$-scission type reaction of the $\mathrm{C}_{\alpha}$-radical and homolytic cleavage of the $\beta$-ether bond in the quinone methide intermediate, respectively. These pathways have been confirmed by the studies of kinetic deuterium isotope effects on product formation from regiospecifically deuterated dimers [53].

Pathway B occurs more effectively than pathway A, with onset temperatures of 260 and $360^{\circ} \mathrm{C}$, respectively [51]. This is explained by the number of radicals formed; three radicals are formed from the phenoxy radical intermediate in pathway $\mathrm{B}$, which increases the radical concentration, whereas the number of radical species does not change in pathway A. Thus, this suggests an important role of the phenolic end groups as radical sensitizers. This proposal is supported by experimental results which have shown that the reactivity of pathway A of Non-Ph dimers significantly increases when $\mathrm{Ph}$ dimer is mixed into the system [53]. An $\alpha, \beta$-diether trimer [1-(4-(3,4-dimethoxybenzoyloxy)-3-methoxyphenyl)-2(2-methoxyphenoxy)-1-propanol], can be used to represent the benzyl ether derivative of the model dimer, and has an onset temperature of $320^{\circ} \mathrm{C}$. The reactivity of this species can be reasonably explained by the formation of a phenoxy radical intermediate of the dimer through homolysis of the benzyl ether (model $\alpha$-ether bond) [51] These cleavage temperatures coincide well with the DTG peak $\left(350^{\circ} \mathrm{C}\right)$, which corresponds to the primary pyrolysis of lignins.

\section{Pathway $\underline{A}$}

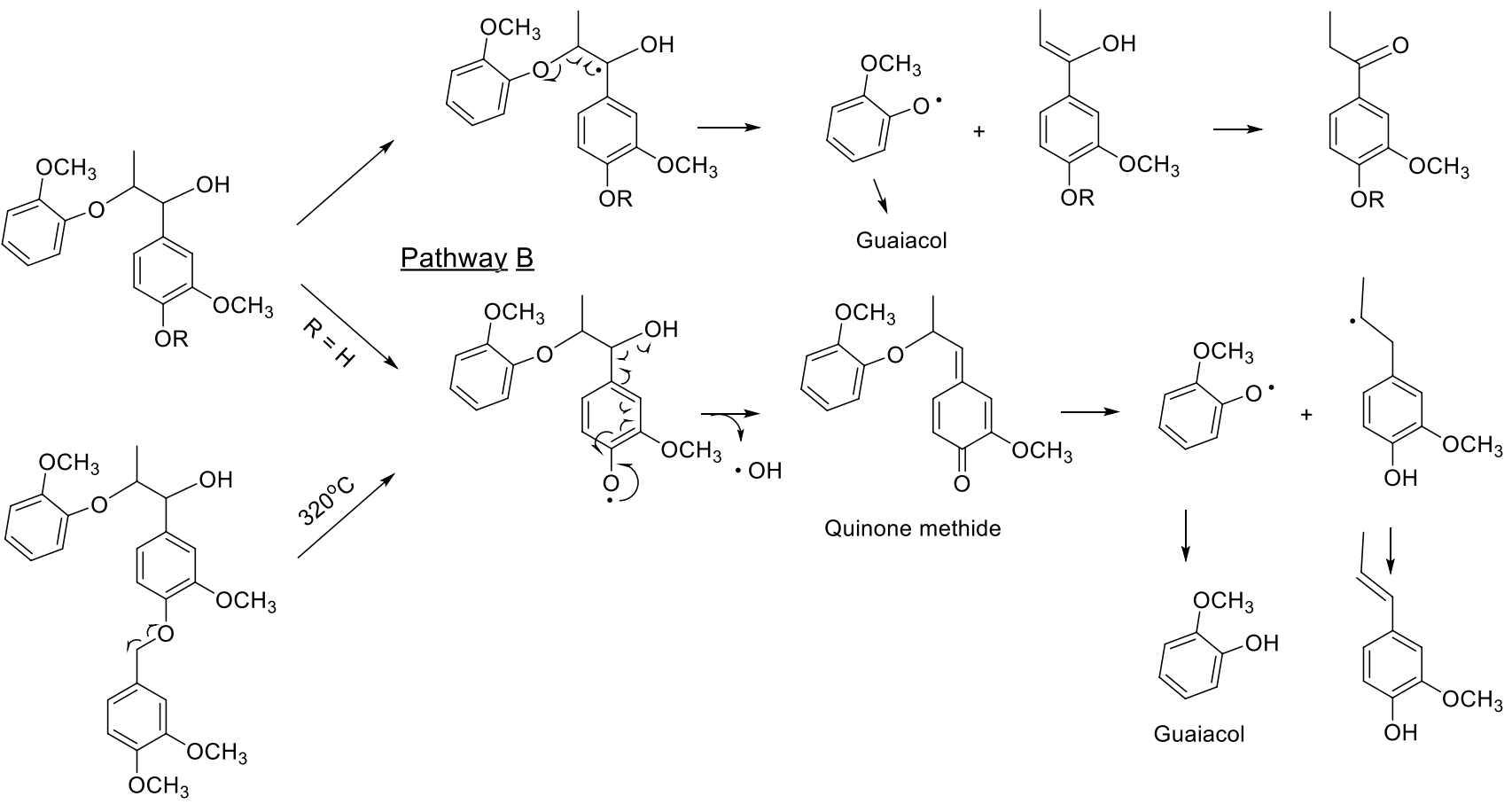

Fig. 7 Proposed radical chain mechanisms for the cleavage of lignin ether bonds 


\section{Re-polymerization and side-chain conversion}

The $\mathrm{Ph} \beta$-ether dimer (guaiacylglycerol- $\beta$-guaiacyl ether) gives coniferyl alcohol in a $30.4 \mathrm{~mol} \%$ yield, representing $60 \mathrm{~mol} \%$ of the decomposition products of this dimer [47]. Cinnamyl alcohols, such as coniferyl alcohol, are the most important primary products in lignin pyrolysis. However, the contributions of cinnamyl alcohols in the pyrolyzates from wood and isolated lignins are much lower than expected from studies using model compounds. Coniferyl aldehyde, isoeugenol, dihydroconiferyl alcohol, 4-vinylguaiacol and vanillin are more important products (in the case of G-lignin pyrolysis). Only direct mass spectrometric analysis of the pyrolyzates from wood and lignin samples, without cooling, indicate significant contributions of coniferyl alcohol (MW: 180) and sinapyl alcohol (MW: 210) [7]. These apparently contradictory observations can be explained by the propensity of coniferyl alcohol and sinapyl alcohol to undergo secondary pyrolysis reactions, particularly polymerization reactions [82-85].

The relative evaporation/polymerization/side-chain conversion efficiency of trans-coniferyl alcohol has been studied by pyrolysis in an open-top reactor system $\left(200-350^{\circ} \mathrm{C}\right.$ under nitrogen, heating period: $5 \mathrm{~min}$ ) [85]. Evaporation of coniferyl alcohol started around $200-250^{\circ} \mathrm{C}$, and competed with secondary pyrolysis reactions, such as polymerization and side-chain conversion reactions. All these processes were enhanced at higher pyrolysis temperatures and completed at $300{ }^{\circ} \mathrm{C}$, where approximately $70 \%$ of the polymerization products were formed along with evaporated coniferyl alcohol (15\%) and side-chain conversion products (15\%). Thus, at the DTG peak of $350^{\circ} \mathrm{C}$ for lignin, secondary pyrolysis reactions, particularly re-polymerization reactions, reduce the coniferyl alcohol yield after it is formed, during the pyrolysis of G-type lignin.

Coniferyl aldehyde (an oxidation product), dihydroconiferyl alcohol ( $\mathrm{R}$ : $-\mathrm{CH}_{2}-\mathrm{CH}_{2}-\mathrm{CH}_{2} \mathrm{OH}$ ) and isoeugenol (reduction products) are all formed as side chain conversion products, together with cis-coniferyl alcohol and 4-vinylguaiacol [85]. Thus, some redox reactions evidently take place during the pyrolysis of coniferyl alcohol to form products that are quite similar to the pyrolyzates obtained from the pyrolysis of natural lignins [86]. Radical and quinone methide mechanisms have been postulated to explain the formation of the side-chain conversion products [85]. Notably, large amounts of hydrogen radicals exist in the pyrolysis environment, which reduce side-chain double bonds. $\beta$-Scission type reactions, such as the conversion of $\cdot \mathrm{C}_{\gamma}-\mathrm{OH}$ to $\mathrm{C}_{\gamma}=\mathrm{O}$ (coniferyl aldehyde), act as a source of hydrogen radicals.

It has been suggested that a quinone methide mechanism operates in the polymerization of coniferyl alcohol, based on the chemical structures of the dimers isolated from the pyrolysis of coniferyl alcohol in the presence of creosol (4-methylguaiacol) at $250^{\circ} \mathrm{C}$ [84]. Hence, the polymerization reactivity of coniferyl alcohol is reduced by methylation of the phenolic hydroxyl group of the coniferyl alcohol. The stable methylated coniferyl alcohol is copolymerized with coniferyl alcohol during pyrolysis [85], which shows that coniferyl alcohol structures can add to the repeating phenylpropane units. The guaiacol derivatives with conjugated $\mathrm{C}_{\alpha}=\mathrm{C}_{\beta}$ side-chains are much more reactive than those with $\mathrm{C}_{\alpha}-\mathrm{OR}$ groups, which are the structures typically observed in natural lignins [84]. A radical chain vinyl condensation mechanism has been proposed to explain the polymerization of 4-vinylguaiacol and its methyl ether derivatives [84]. Thus, primary pyrolysis reactions that form side-chain double bonds promote condensation of natural lignins. Methylation of the phenolic hydroxyl groups of MWL prevents pyrolysis reactions that arise from the reactive phenolic end groups and considerably inhibits condensation reactions [20].

\section{Competitive processes during primary pyrolysis}

Lignin primary pyrolysis pathways (Fig. 8, shows G-type lignin pyrolysis) have been proposed based on the investigation of the influences of 1,2,3,10b-tetrahydrofluoranthene, a hydrogen donor, and diphenoxybenzene (DPB), an aprotic solvent $[86,87]$. In DPB, the polymerization of coniferyl alcohol and sinapyl alcohol were effectively suppressed. Both DPB and H-donors were required for the effective formation of monomers from wood and MWLs, suggesting that lignin ether bonds undergo homolysis. The expected primary product of this reaction was a coniferyl alcohol radical that is stabilized by the $\mathrm{H}$-donor. The $\mathrm{H}$-donor also promotes side-chain reduction of the resulting coniferyl alcohol to form dihydroconiferyl alcohol and isoeugenol as the major monomers [86]. Under normal pyrolysis conditions, without the addition of any $\mathrm{H}$-donors, the amount of H-donors is not sufficient to stabilize all the radical species formed through cleavage of ether linkages. Hence, primary radicals tend to undergo radical coupling reactions to form polymerization products.

The relative oxidation/reduction efficiency of sidechains of coniferyl alcohol varies depending on the pyrolysis temperature. At relatively low temperatures (for example $250^{\circ} \mathrm{C}$ ), coniferyl aldehyde, an oxidation product, is the major monomer from lignin pyrolysis [24, 86]. In this case, the pyrolysis environment is expected to be radical conditions, which enhance hydrogen abstraction reactions [86]. The $\mathrm{C}_{\gamma}$-hydrogen atom of coniferyl alcohol, which is at the conjugated allyl position, is the main site of $\mathrm{H}$-abstraction; the abstraction of hydrogen then leads to production of coniferyl aldehyde. However, by increasing the pyrolysis temperature to $>350{ }^{\circ} \mathrm{C}$, the pyrolysis environment 


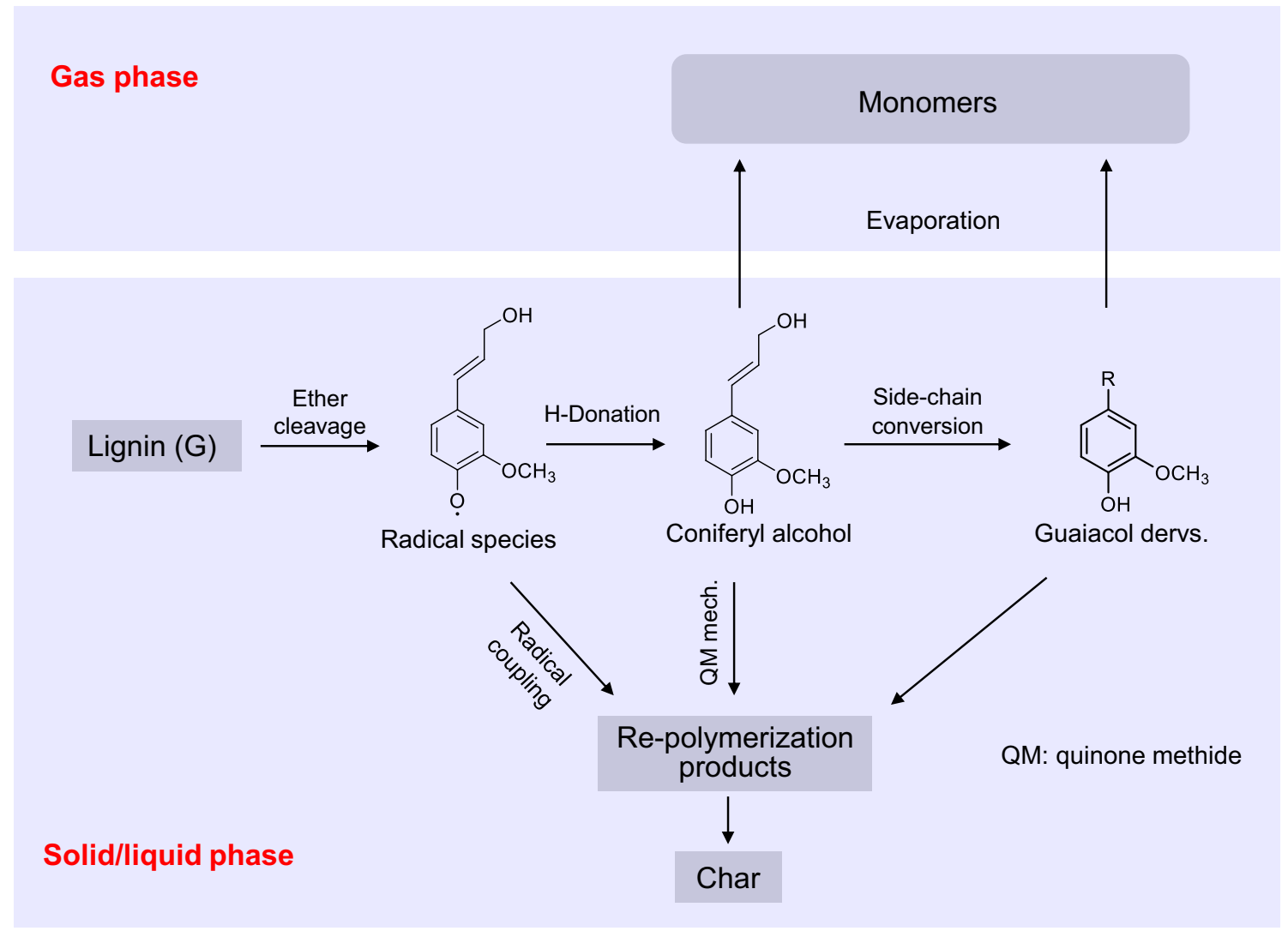

Fig. 8 Competitive pathways from coniferyl alcohol radical, a primary pyrolysis product, as proposed for the production of monomers and char during pyrolysis of G-type lignin at the primary pyrolysis stage $\left(200-400^{\circ} \mathrm{C}\right)$

becomes richer in H-donor species (H-radicals), which results in increased monomer yields and the formation of side-chain reduction products such as dihydroconiferyl alcohol and isoeugenol.

Polymerization of the primary products by radical and quinone methide mechanisms can compete with side-chain conversion and evaporation processes [86]. Evaporation is the key step to recovering monomeric products. Otherwise, products polymerize and are finally converted to solid carbonized products. During the polymerization process, condensed $(\mathrm{C}-\mathrm{C})$ linkages are formed more preferably than ether $(\mathrm{C}-\mathrm{O})$ linkages based on the hard/soft, acid/ base rule. The resulting polymerization products contain more $\mathrm{C}-\mathrm{C}$ linkages, which are more resistant to further depolymerization.

The polymer effect also promotes polymerization and side-chain conversion of lignin primary pyrolysis intermediates [86]. Cleavage of ether linkages at the terminal endgroups of lignin macromolecules leads to direct formation of monomers, whereas the cleavage of ether linkages within the polymer, does not lead to immediate formation of monomers because of the polymeric nature of the intermediates formed. In these circumstances, pyrolyzates remain in the heating zone and undergo polymerization and side-chain conversions. Thus, the monomer yield is reduced and the yield of char and side-chain conversion products increases.

Sinapyl alcohol, the corresponding primary product from S-type lignins, exhibits similar reactivity to that observed for the pyrolysis of coniferyl alcohol. However, sinapyl alcohol shows greater radical sensitivity at a relatively high pyrolysis temperature of $350^{\circ} \mathrm{C}$ [87].

\section{Secondary pyrolysis reactions $\left(>400{ }^{\circ} \mathrm{C}\right)$}

\section{Change in aromatic substitution pattern}

As shown in Fig. 9, homolytic cleavage of the $\mathrm{O}-\mathrm{CH}_{3}$ bonds attached to the lignin aromatic rings occurs effectively at $\sim 450{ }^{\circ} \mathrm{C}$, associated with an ipso rearrangement starting from the phenoxy radical of guaiacol [88]. Intramolecular $\mathrm{H}$-abstraction at the methyl group, by a phenoxy radical (reaction c) and subsequent 1,2-aryl migration (reaction e) have been proposed to account for this transformation [88, 89]. The 1,2-aryl migration product is further converted into o-quinone methide (reaction g), 


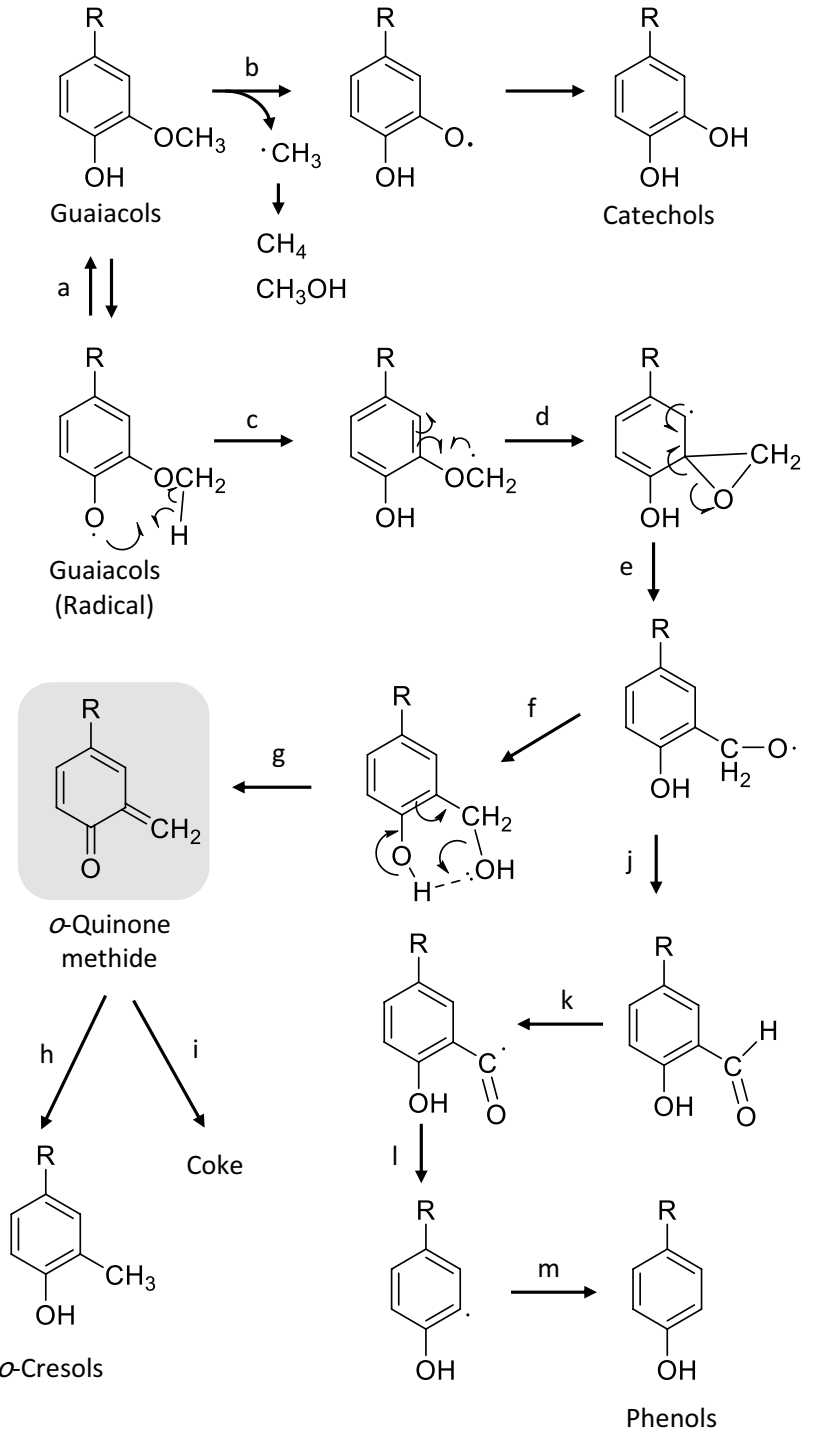

Fig. 9 Pathways for the conversion of guaiacols, the primary pyrolysis products from G-type lignin, into catechols, $O$-cresols, phenols and coke at the secondary pyrolysis stage $\left(>400^{\circ} \mathrm{C}\right)$

a key intermediate [90, 91], which is subsequently hydrogenated to $o$-cresol (reaction h). Demethoxylation occurs by $\alpha$-scission of the formyl radical (reaction l) formed by $\mathrm{H}$-abstraction from $o$-hydroxybenzaldehyde (reaction k) $[88,92]$. Thus, syringols formed as primary pyrolysis products from S-type lignins are gradually converted into guaiacols and phenols [92]. Owing to these reactions, the aromatic substituents change from $-\mathrm{OCH}_{3}$ to $-\mathrm{OH},-\mathrm{CH}_{3}$, and $-\mathrm{H}$ groups. These reactions may proceed in both gas- and liquid/solid-phase reactions [9].

Concentrations of $\mathrm{H}$-acceptors (radicals) and $\mathrm{H}$-donors play important roles in these pathways. Catechol and methyl radicals formed by the homolysis reaction $b$ are stabilized by the formation of catechol and methane, respectively, where two $\mathrm{H}$-donors can donate hydrogen atoms to these radicals. Otherwise, these radicals are consumed by radical coupling reactions including methylation of aromatic rings by addition of the methyl radical to $\mathrm{C}$-centered radicals that form as resonance structures of phenoxy radicals [92]. Methanol is also produced by coupling of methyl and hydroxyl radicals.

However, the formation of products via the $\mathrm{OCH}_{3}$ rearrangement pathway requires both $\mathrm{H}$-acceptors and $\mathrm{H}$-donors. The numbers of $\mathrm{H}$-acceptors/H-donors required for the formation of $o$-quinone methide and $o$-cresol from guaiacol are $1 / 1$ and $1 / 3$, respectively [93]. Accordingly, the selectivity for the homolysis and rearrangement pathways can be controlled by changing the concentrations of $\mathrm{H}$-acceptors/H-donors in the pyrolysis environment [93, 94]. Asmadi et al. [93] observed that these reactions are promoted in the presence of coking reactions. On the basis of these results it was suggested that polyaromatization during charring reactions produces $\mathrm{H}$-radicals, which act as $\mathrm{H}$-acceptors and $\mathrm{H}$-donors to promote the $\mathrm{OCH}_{3}$ rearrangement pathway. Smaller H-radicals are preferable for these reactions, because all the intermediates involved favor a linear transition state, which maximizes the interaction between the radical orbital and the vacant $\sigma^{*}$ orbital of the bond to be cleaved.

\section{Coking and PAH formation}

Coking of lignin-derived volatile intermediates occurs in several stages depending on the pyrolysis temperature. First, low-temperature coke formation (first stage coking) is observed along with the $\mathrm{OCH}_{3}$ rearrangement pathway. It has been suggested that this coking reaction is closely related to the o-quinone methide intermediate (Fig. 9). Only guaiacols with methoxyl groups produced a significant amount of coke in the reactions of various compounds bearing guaiacol-, cresol-, catechol- and phenol-type aromatic nuclei (in a closed ampoule $/ \mathrm{N}_{2} / 600^{\circ} \mathrm{C} / 80 \mathrm{~s}$, with a final temperature of $569^{\circ} \mathrm{C}$ ) and 2-ethoxyphenol produced 2,3-benzofuran instead of coke [95]. The 2,3-benzofuran formation can be reasonably explained by the reactivity of the $o$-quinone methide bearing an allyl moiety, which can be converted to 2,3-benzofuran by cyclization of the allyl radical intermediate formed by $\mathrm{H}$-abstraction.

When catechol-type aromatic rings decompose into gas and other products at high temperatures $\left(>550^{\circ} \mathrm{C}\right)$, catechols/pyrogallols and cresols/xylenols tend to produce coke (second stage coking) [96]. The same o-quinone methide type intermediates can be considered for coking from $o$-cresols/xylenols, which can form by abstraction of phenolic and benzylic hydrogen atoms. The coke yield increases as the number of methyl groups in the molecules increase: $o$-cresol $(6.1 \mathrm{wt} \%)<2$,4-xylenol $(12.8 \mathrm{wt} \%)$, 
2,6-xylenol (9.2 wt\%) <2,4,6-trimethylphenol (23.5 wt\%) (in a closed ampoule $/ \mathrm{N}_{2} / 600^{\circ} \mathrm{C}$ ) [96]. Therefore, methoxyl and methyl groups are important structural elements for coke formation. Coking from catechols/pyrogallols may arise from reactive fragments, such as acetylene and propagyl radical, as will be described later.

Regarding the reactivities of G- and S-type lignins, the coking reactivity is greater for syringol than for guaiacol, as model lignin primary pyrolyzates. The additional $\mathrm{OCH}_{3}$ group in syringol, effectively doubles the opportunity for coke formation [92]. Alternatively, the yields of GC/MSdetectable monomers from syringol are lower than those from guaiacol.

PAHs start to form at $600^{\circ} \mathrm{C}$ and their production is accelerated at high temperatures $>700^{\circ} \mathrm{C}$ [97-99]. Wornat et al. [100] reported 59 PAHs from pyrolysis of catechol at $1000^{\circ} \mathrm{C}$ ranging in size up to eight aromatic rings (residence time $0.4 \mathrm{~s}$ ). In these studies it was also pointed out that the PAH compositions of catechol pyrolysis resembled those of coal pyrolysis. PAH and soot formation during the combustion of hydrocarbon fuels is well understood, and acetylene, propagyl and cyclopentadienyl radicals are considered to be key precursors for the formation of the first aromatic ring [101, 102]. For example, addition of gaseous acetylene to radical sites followed by cyclization, combination of propagyl radicals, and coupling reactions of cyclopentadienyl radicals have been proposed to account for the construction of benzene rings. Ledesma et al. [103] reported propyne, propanediene and cyclopentadiene as stable forms of propagyl and cyclopentadienyl radicals along with acetylene (in maximum yields of $~ 1.6,0.5, \sim 7$, and $\sim 20 \%$, respectively) from the gas phase pyrolysis of catechol in the temperature range $600-1000{ }^{\circ} \mathrm{C}$ (residence time $0.4 \mathrm{~s}$ ). These compounds are key intermediates for ring-growth reactions that produce PAHs. Ledesma et al. [104] measured $E_{\mathrm{a}}$ values for the formation of PAHs from catechol in the range of $50-110 \mathrm{kcal} \mathrm{mol}^{-1}$. The values increased for structures with different numbers of rings in the order, 2-rings $<3$-rings $<4$-rings $<5$-rings $<6$-rings.

\section{Elimination of aromatic substituents by replacement with hydrogen}

Hydrogen-transfer reactions in aromatic rings during coal liquefaction in $\mathrm{H}$-donor solvents, such as tetralin are reported to cleave the strong bonds between aromatic rings and aliphatic side-chains [105, 106]. Aromatic methyl substituents in lignin pyrolyzates, which are formed by $\mathrm{OCH}_{3}$ rearrangements, methylation by methyl radicals, and homolysis of $\mathrm{C}-\mathrm{C}$ bonds in ethyl and propyl side-chains, are also known to cleave in the secondary pyrolysis reaction stage [96, 107, 108]. For example, demethylation was reported to be the main reaction of $o$-cresol and 2,6-xylenol at $600{ }^{\circ} \mathrm{C}$ (in an ampoule, $600 \mathrm{~s}$ ), which produced $18.0 \mathrm{wt} \%$ and $18.2 \mathrm{wt} \%$ of the demethylation products, respectively, along with coke [96].

Demethylation reactions occur more selectively at the ortho and para positions to the phenolic hydroxyl group, as can be seen for pyrolysis of 2,3-xylenol, which gives $m$-cresol (32.6 wt\%) rather than $o$-cresol (1.4 wt\%) [96]. Demethylation is believed to proceed by replacement with hydrogen radicals (Fig. 10A). Thus, the higher reactivities of the $o$ - and $p$-methyl groups should be explained by this mechanism. A radical coupling mechanism (Fig. 10b) [96] can explain the selectivity of this reaction, although further study is necessary to confirm this proposition. Coupling of phenoxy and hydrogen radicals proceeds only at the $o$ - and $p$-positions, owing to the resonance structures of the intermediates, and the resulting cyclohexanedienone has a weak $\mathrm{C}-\mathrm{CH}_{3}$ bond. The calculated BDE is reduced from 110.5 to $60.3 \mathrm{kcal} \mathrm{mol}^{-1}$. This is a similar reaction type to that observed for low-temperature homolysis of $\beta$-ether linkages of quinone methide intermediates. The strong electron-withdrawing ability of the conjugated carbonyl moiety decreases the $\mathrm{BDE}$ of the $\mathrm{C}-\mathrm{CH}_{3}$ bond.

\section{Degradation of aromatic rings into gas}

When the pyrolysis temperature is further increased to $550-600^{\circ} \mathrm{C}$, decomposition of catechols and pyrogarolls into non-condensable gases (mainly $\mathrm{CO}$ ) occurs. Ledesma et al. [103] reported that gas-phase pyrolysis of catechol gives CO (approximately $50 \mathrm{wt} \%$ ) and acetylene $(20 \mathrm{wt} \%)$ at $800^{\circ} \mathrm{C}$ (with residence time $0.4 \mathrm{~s}$ ). The gas formation mechanism has also been explained as illustrated in Fig. 11. The mechanism is based on reports that suggest the phenoxy radical undergoes unimolecular decomposition into $\mathrm{CO}$ and a cyclopentadienyl

A

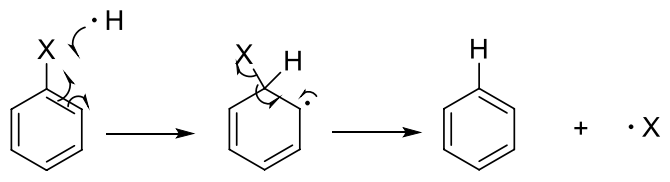

B

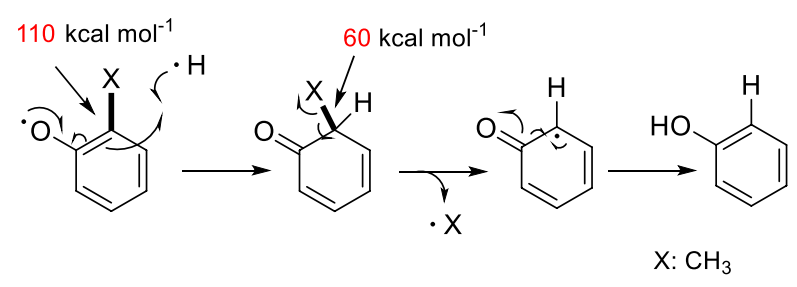

Fig. 10 Replacement of aromatic substituents by hydrogen radicals 
radical. The catechol radical decomposes into $\mathrm{CO}$ and a cycrolentadienol-lyl radical, which then further decomposes to cyclopentadienone. The cyclopentadienone fragments decompose into $\mathrm{CO}$ and two acetylene molecules. Although the exact details of the formation mechanism are unknown, pyrogallols that are formed from the S-type lignins typically produce large amounts of $\mathrm{CO}_{2}$ along with CO [96].

The gas formation reactivities of cresols/xylenols are lower than those of catechols/pyrogallols and the compositions of the gaseous products are very different for these two types of products [96]. Cresols/xylenols tend to produce $\mathrm{CH}_{4}$ and $\mathrm{H}_{2}$ rather than $\mathrm{CO}$ and $\mathrm{CO}_{2}$, along with demethylation products and coke at $600{ }^{\circ} \mathrm{C}$ in an ampoule. Methane is formed by $\mathrm{H}$-donation to methyl radicals formed during demethylation and the coking process produces $\mathrm{H}$-radicals during polyaromatization, which leads to the formation of $\mathrm{H}_{2}$. The $\mathrm{CH}_{4}$ yield is related to the number of methyl groups in cresols/xylenols, and the yield increases in the order, $o$-cresol $(2.8 \mathrm{wt} \%)<2$,4-xylenol (5.9 wt\%) and 2,6-xylenol $(6.0 \mathrm{wt} \%)<1,3,5$-trimethylphenol (9.5 wt \%). The $\mathrm{H}_{2}$ yield also increases in this order following the same order as the coke yield.

\section{Lignin pyrolysis in cell walls}

Wood cell walls, which have thicknesses of 1-10 $\mu \mathrm{m}$, are a heterogeneous layered material, in which cellulose microfibrils are filled with a matrix consisting of hemicellulose and lignin [109]. Accordingly, the heterogeneous nature of wood cell wall structures should be considered when assessing the pyrolysis reactions of wood constituent polymers. Lignins in the matrix will undergo pyrolysis alongside the pyrolysis of hemicellulose. The different chemical compositions of lignin and hemicellulose in softwoods and hardwoods may also affect the pyrolysis of these components in wood cell walls.

As discussed above, the majority of ether linkages between phenylpropane units are cleaved homolytically to form radical species, except for $\alpha$-ether bonds at phenolic

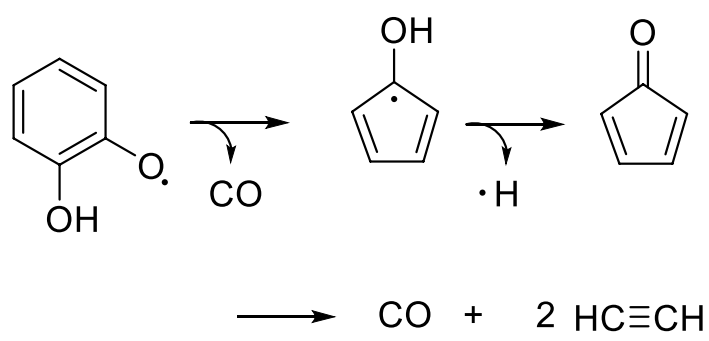

Fig. 11 Mechanism of the reaction of catechol radicals during pyrolysis of catechol end groups. Conversely, the primary pyrolysis of cellulose and hemicellulose gives non-radical species, because heterolytic cleavage of glycosidic $\mathrm{C}-\mathrm{O}$ bonds is the main primary pyrolysis reaction [110-112]. These different types of the primary pyrolysis products may interact with each other.

The radical chain reactivity of lignin in wood has been addressed by an in situ dimer probe method, which is based on changes in the reactivity of dimers in the presence of wood and its constituent polymers [113]. Strong interactions between lignin and wood polysaccharides have been indicated by this method, which also depend on the type of polysaccharide and the pyrolysis temperature [113]. Xylan activates the radical chain reactions of dimers, whereas glucomannan strongly inhibits non-phenolic dimers. Cellulose inhibits the radical chain reactions of lignins at temperatures below $300^{\circ} \mathrm{C}$, although these effects are minimal at temperatures above $350^{\circ} \mathrm{C}$, when cellulose rapidly decomposes.

Hydrogen donors may play important roles during primary pyrolysis of lignins in wood, because lignin primary pyrolysis occurs by homolysis mechanisms. Wood polysaccharides and their pyrolysis products may act as the $\mathrm{H}$-donors to stabilize lignin-derived radicals, which results in an increase of the monomer yield. This efficiency is reported to be greater for pyrolysis of Japanese beech wood (a hardwood) than that of Japanese cedar wood (a softwood), probably due to the different roles of xylan and glucomannan pyrolysis [87].

Significant interactions have also been suggested in the secondary pyrolysis reaction stage. Levoglucosan, an important primary product from cellulose, efficiently polymerizes into polysaccharides by conversion of vapor into a molten substance under cooling [114, 115]. This polymerization reaction is suppressed in the presence of lignin-derived products [116, 117]. A stabilization mechanism has been proposed; proton donation to levoglucosan through intermolecular hydrogen bonding acts as an acid catalyst to promote the polymerization, which is effectively inhibited by the lignin-derived products through hydrogen bonding between aromatic $\pi$-electrons and $\mathrm{OH}$ groups of levoglucosan [112].

During the gas-phase secondary pyrolysis reaction stage, the monomer yields from Japanese cedar MWL increased from 5.3 to $20.2 \mathrm{wt} \%$ under the influence of cellulose pyrolysis, and the selectivity for catechol over cresols/xylenol products increased from 0.9 to 5.5 [94]. This can be reasonably explained by the action of cellulose-derived products as $\mathrm{H}$-donors that stabilize the catechol radicals and suppress the concentration of guaiacol radicals, which start the $\mathrm{OCH}_{3}$ rearrangement pathway (Fig. 9). 


\section{Conclusions and future prospects}

A better understanding of lignin pyrolysis reactions is important for developing improved thermochemical conversion technologies to effectively utilize lignin for the production of biochemicals, biomaterials, and biofuels. This review article summarizes the current understanding of lignin pyrolysis reaction pathways and mechanisms. However, there remains much work still to be done to understand lignin pyrolysis and gasification behaviors. Recently, many theoretical studies have been conducted to estimate the BDEs of linkages in lignin and to help propose reaction mechanisms. However, there is a particular need to accumulate more experimental data to effectively support these calculation results.

Acknowledgements Publishing and availability of open access articles were supported by JSPS KAKENHI Grant Number JP16HP2001. This work was partially sponsored by JSPS KAKENHI Grant Number $16 \mathrm{H} 04954$.

Open Access This article is distributed under the terms of the Creative Commons Attribution 4.0 International License (http:// creativecommons.org/licenses/by/4.0/), which permits unrestricted use, distribution, and reproduction in any medium, provided you give appropriate credit to the original author(s) and the source, provide a link to the Creative Commons license, and indicate if changes were made.

\section{References}

1. Lieth H, Whittaker RH (eds) (1975) Primary productivity of the biosphere. Springer-Verlag, Berlin

2. Czernik S, Bridgwater AV (2004) Overview of applications of biomass fast pyrolysis oil. Energy Fuels 18: 590-598

3. Bridgwater AV (2012) Review of fast pyrolysis of biomass and product upgrading. Biomass Bioenergy 38: 68-94

4. Anis S, Zainal ZA (2011) Tar reduction in biomass producer gas via mechanical, catalytic and thermal methods: A review. Renew Sust Energ Rev 15:2355-2377

5. Shen Y, Yoshikawa K (2013) Recent progress in catalytic tar elimination during biomass gasification or pyrolysis-a review. Renew Sust Energ Rev 21:371-392

6. Devi L, Ptasinski KJ, Janssen JJG (2003) A review of the primary measures for tar elimination in biomass gasification processes. Biomass Bioenrgy 24:125-140

7. Evans RJ, Milne TA (1987) Molecular characterization of the pyrolysis of biomass 1. Fundamentals. Energy Fuels 1:123-137

8. Adler E (1977) Lignin chemistry-past, present and future. Wood Sci Technol 11:169-218

9. Asmadi M, Kawamoto H, Saka S (2011) Gas- and solid/liquid-phase reactions during pyrolysis of softwood and hardwood lignins. J Anal Appl Pyrolysis 92:417-425

10. Sipilä K, Kuoppala E, Fagernäs L, Oasmaa A (1998) Characterization of biomass-based flash pyrolysis oils. Biomass Bioenerg 14: 103-113
11. Branca C, Giudicianni P, Di Blasi C (2003) GC/MS characterization of liquids generated from low-temperature pyrolysis of wood. Ind Eng Chem Res 42:3190-3202

12. Hosoya T, Kawamoto H, Saka S (2008) Secondary reactions of lignin-derived primary tar components. J Anal Appl Pyrolysis $83: 78-87$

13. Haw JF, Schultz TP (1985) ${ }^{13} \mathrm{C}$ CP MAS NMR and FT-IR study of low-temperature lignin pyrolysis. Holzforschung 39:289-296

14. Pindoria RV, Lim JY, Hawkes JE, Lazaro MJ, Herod AA, Kandiyoti R (1997) Structural characterization of biomass pyrolysis tars/oils from eucalyptus wood waste: effect of $\mathrm{H}_{2}$ pressure and sample configuration. Fuel 76:1013-1023

15. Sharma RK, Wooten JB, Baliga VL, Lin X, Geoffrey Chan W, Hajaligol MR (2004) Characterization of chars from pyrolysis of lignin. Fuel 83:1469-1482

16. Hosoya T, Kawamoto H, Saka S (2008) Pyrolysis gasification reactivities of primary tar and char fractions from cellulose and lignin as studied with a closed ampoule reactor. J Anal Appl Pyrolysis 83:71-77

17. Dufour A, Castro-Diaz M, Brosse N, Bouroukba M, Snape C (2012) The origin of molecular mobility during biomass pyrolysis as revealed by in situ ${ }^{1} \mathrm{H}$ NMR spectroscopy. ChemSusChem 5:1258-1265

18. Dufour A, Castro-Díaz M, Marchal P, Brosse N, Olcese R, Bouroukba M, Snape C (2012) In situ analysis of biomass pyrolysis by high temperature rheology in relations with ${ }^{1} \mathrm{H}$ NMR. Energ Fuels 26: 6432-6441

19. Fenner RA, Lephardt JO (1981) Examination of the thermaldecomposition of kraft pine lignin by fourier-transform infrared evolved gas-analysis. J Agric Food Chem 29:846-849

20. Nakamura T, Kawamoto H, Saka S (2008) Pyrolysis behavior of Japanese cedar wood lignin studied with various model dimers. J Anal Appl Pyrolysis 81:173-182

21. Scholze B, Meier D (2001) Characterization of the waterinsoluble fraction from pyrolysis oil (pyrolytic lignin). Part I. PY-GC/MS, FTIR, and functional groups. J Anal Appl Pyrolysis $60: 41-54$

22. Genuit W, Boon JJ, Faix O (1987) Characterization of beech milled wood lignin by pyrolysis-gas chromatography photoionization mass-spectrometry. Anal Chem 59:508-513

23. Ralph J, Hatfield RD (1991) Pyrolysis-GC-MS characterization of forage materials. J Agric Food Chem 39:1426-1437

24. Arias ME, Polvillo O, Rodríguez J, Hernández M, GonzálezPérez JA, González-Vila FJ (2006) Thermal transformations of pine wood components under pyrolysis/gas chromatography/ mass spectrometry conditions. J Anal Appl Pyrolysis 77:63-67

25. Greenwood PF, van Heemst JDH, Guthrie EA, Hatcher PG (2002) Laser micropyrolysis GC-MS of lignin. J Anal Appl Pyrolysis 62:365-373

26. Alen R, Kuoppala E, Oesch P (1996) Formation of the main degradation compound groups from wood and its components during pyrolysis. J Anal Appl Pyrolysis 36:137-148

27. Kuroda K (1994) Pyrolysis of arylglycol- $\beta$-propylphenyl ether lignin model in the presence of borosilicate glass fibers. I. Pyrolysis reactions of $\beta$-ether compounds. J Anal Appl Pyrolysis 30:173-182

28. Kuroda K (1995) Contribution of an oxirane intermediate in the pyrolytic cleavage of the $\beta$-aryl ether structure in lignin: Pyrolysis of 3,4-dimethoxyphenyloxirane. J Anal Appl Pyrolysis 35:53-60

29. Akazawa M, Kojima Y, Kato Y (2016) Effect of pyrolysis temperature on the pyrolytic degradation mechanism of $\beta$-aryl ether linkages. J Anal Appl Pyrolysis 118:164-174

30. Kuroda K, Nakagawa-izumi A, Ashitani T, Fujita K (2009) Tetramethylammonium hydroxide (TMAH) 
thermochemolysis of 2-arylcoumaran lignin model compounds. J Anal Appl Pyrolysis 86:185-191

31. Kuroda K, Ashitani T, Fujita K, Hattori T (2007) Thermal behavior of $\beta$ subunits in lignin: pyrolysis of 1,2-diarylpropane-1,3-diol-type lignin model compounds. J Agr Food Chem 55:2770-2778

32. Kuroda K, Nakagawa-izumi A (2006) Analytical pyrolysis of lignin: Products stemming from $\beta-5$ substructures. Org Geochem 37:665-673

33. Nakagawa-izumi A, Kuroda K, Ozawa T (2004) Thermochemolytic behavior of $\beta$ lignin structures in the presence of tetramethylammonium hydroxide (TMAH). Org Geochem 35:763-774

34. Faix O, Meier D, Fortmann I (1988) Pyrolysis-gas chromatography-mass spectrometry of two trimeric lignin model compounds with alkyl-aryl ether structure. J Anal Appl Pyrolysis 14:135-148

35. Kuroda K, Nakagawa-izumi (2005) Tetramethylammonium hydroxide thermochemolysis of guaiacyl-syringyl and guaiacyl dehydrogenation polymers. Org Geochem 36:53-61

36. Jensen A, Dam-Johansen K, Wojtowicz MA, Serio MA (1998) TG-FTIR study of the influence of pottasium chloride on wheat straw pyrolysis. Energy Fuels 12: 929-938

37. Bassilakis R, Carangelo RM, Wojtowicz MA (2001) TGFTIR analysis of biomass pyrolysis. Fuel 80:1765-1786

38. Biagini E, Barontini F, Tognotti L (2006) Devolatilization of biomass fuels and biomass componenst studied by TG/FTIR technique. Ind Eng Chem Res 45:4486-4493

39. Liu Q, Wang S, Zheng Y, Luo Z, Cen K (2008) Mechanism study of wood lignin pyrolysis by using TG-FTIR analysis. J Anal Appl Pyrolysis 82:170-177

40. Brežný R, Mihálov V, Kováčik V (1983) Low-temperature thermolysis of lignin 1 . Reactions of $\beta-O-4$ model compounds. Holzforschung 37:199-204

41. Brežný R, Šurina I, Košik M (1984) Low-temperature thermolysis of lignin 2 . Thermofractography and thermal-analysis of $\beta-O-4$ model compounds. Holzforschung 38:19-24

42. Klein MT, Virk PS (1983) Model pathways in lignin thermolysis 1. Phenthyl phenyl ether. Ind Eng Chem Fund 22: 35-45

43. Autrey ST, Alnajjar MS, Nelson DA, Franz JA (1991) Absolute rate constants for the $\beta$-scission raction of the 1-phenetyl2-phenoxypropyl radical-a model for radical reactions of lignin. J Org Chem 56:2197-2202

44. Britt PF, Buchanan AC, Malcolm EA (1995) Thermolysis of phenethyl phenyl ether-a model for ether linkages in lignin and low-rank coal. J Org Chem 60:6523-6536

45. Kawamoto H, Horigoshi S, Saka S (2006) Effects of sidechain hydroxyl groups on pyrolytic $\beta$-ether cleavage of phenolic lignin model dimer. J Wood Sci 53:268-271

46. Beste A, Buchanan AC III, Britt PF, Hathorn BC, Harrison RJ (2007) Kinetic analysis of the pyrolysis of phenethyl phenyl ether: computational prediction of alpha/beta-selectivities. J Phys Chem A 111:12118-12126

47. Kawamoto H, Horigoshi S, Saka S (2007) Pyrolysis reactions of various lignin model dimers. J Wood Sci 53:168-174

48. Kawamoto H, Saka S (2007) Role of side-chain hydroxyl groups in pyrolytic reaction of phenolic $\beta$-ether type of lignin dimer. J Wood Chem Technol 27:113-120

49. Kawamoto H, Nakamura T, Saka S (2008) Pyrolytic cleavage mechanisms of lignin-ether linkages: a study on $p$-substituted dimers and trimers. Holzforschung 62:50-56

50. Kawamoto H, Ryoritani M, Saka S (2008) Different pyrolytic cleavage mechanisms of $\beta$-ether bond depending on the side-chain structure of lignin dimers. J Anal Appl Pyrolysis 81:88-94
51. Watanabe T, Kawamoto H, Saka S (2009) Radical chain reactions in pyrolytic cleavage of the ether linkages of lignin model dimers and a trimer. Holzforschung 63:424-430

52. Holmelid B, Kleinert M, Barth T (2012) Reactivity and reaction pathways in thermochemical treatment of selected lignin-like model compounds under hydrogen rich conditions. J Anal Appl Pyrolysis 98:37-44

53. Watanabe T, Kawamoto H, Saka S (2015) Pyrolytic reactivities of deuterated $\beta$-ether-type lignin model dimers. J Anal Appl Pyrolysis 112:23-28

54. Domburg GE, Sergeeva VN, Zheibe GA (1970) Thermal analysis of some lignin model compounds. J Thermal Anal 2:419-428

55. Liu JY, Wu SB, Lou R (2011) Chemical structure and pyrolysis response of $\beta-O-4$ lignin model polymer. Bioresources 6 : 1079-1093

56. Uraki Y, Sugiyama Y, Koda K, Kubo S, Kishimoto T, Kadla J (2012) Thermal mobility of $\beta$-O-4-type artificial lignin. Biomacromolecules 13:867-872

57. Chu S, Subrahmanyam AV, Huber GW (2013) The pyrolysis chemistry of a $\beta-O-4$ type oligomeric lignin model compound. Green Chem 15: 125-136

58. Sazanov YN, Gribanov AV (2010) Thermochemistry of lignin. Russ J Appl Chem 83:175-194

59. Gardner DJ, Schultz TP, McGinnis GD (1985) The pyrolytic behavior of selected lignin preparations. J Wood Chem Technol 5:85-110

60. Faix O, Jakab E, Till F, Székely T (1988) Study on low mass thermal-degradation products of milled wood lignins by thermogravimetry-mass-spectrometry. Wood Sci Technol 22:323-334

61. Beste A, Buchanan AC III (2009) Computational study of bond dissociation enthalpies for lignin model compounds. Substituent effects in phenethyl phenyl ethers. J Org Chem 74:2837-2841

62. Younker LM, Beste A, Buchanan AC III (2011) Computational study of bond dissociation enthalpies for substituted $\beta-O-4$ lignin model compounds. ChemPhysChem 12:3556-3565

63. Parthasarathi R, Romero RA, Redondo A, Gnanakaran S (2011) Theroretical study of the remarkably diverse linkages in lignin. J Phys Chem Lett 2:2660-2666

64. Kim S, Chmely SC, Nimlos MR, Bomble YJ, Foust TD, Paton RS, Beckham GT (2011) Computational study of bond dissociation enthalpies for a large range of native and modified lignins. J Phys Chem Lett 2:2846-2852

65. Younker JM, Beste A, Buchanan AC III (2012) Computational study of bond dissociation enthalpies for lignin model compounds: $\beta$ arylcoumaran. Chem Phys Lett 545:100-106

66. Elder T (2013) Bond dissociation enthalpies of a dibenzodioxocin lignin model compound. Energy Fuels 27: 4785-4790

67. Gardrat C, Ruggiero R, Rayez M-T, Rayez J-C, Castellan A (2013) Experimental and theoretical studies of the thermal degradation of a phenolic dibenzodioxocin lignin model. Wood Sci Technol 47:27-41

68. Elder T (2014) Bond dissociation enthalpies of a pinoresinol lignin model compound. Energy Fuels 28: 1175-1182

69. Huang J, He C (2015) Pyrolysis mechanism of $\alpha-O-4$ linkages lignin dimer: a thoretical study. J Anal Appl Pyrolysis 113:655-664

70. Huang J, He C, Liu C, Tong H, Wu L, Wu S (2015) A computational study on thermal decomposition mechanism of $\beta$ linkage lignin dimer. Comput Theor Chem 1054: 80-87

71. Suryan MM, Kafafi SA, Stein SE (1989) Dissociation of substituted anisoles: substituent effects on bond strengths. J Am Chem Soc 111:4594-4600

72. Jarvis MW, Daily JW, Carstensen HH, Dean AM, Sharma S, Dayton DC, Robichaud DJ, Nimlos MR (2011) Direct 
detection of products from pyrolysis of 2-phenethyl phenyl ether. J Phys Chem A 115:428-438

73. Huang X, Liu C, Huang J, Li H (2011) Theory studies on pyrolysis mechanism of phenethyl phenyl ether. Comput Theor Chem 976: 51-59

74. Huang J, Liu C, Wu D, Tong H, Ren L (2014) Density functional theory studies on pyrolysis mechanism of $\beta-O-4$ type lignin dimer model compound. J Anal Appl Pyrolysis 109:98-108

75. Chen L, Ye X, Luo F, Shao J, Lu Q, Fang Y, Wang X, Chen $\mathrm{H}$ (2015) Pyrolysis mechanism of $\beta-O-4$ type lignin model dimer. J Anal Appl Pyrolysis 115:103-111

76. Elder T, Beste A (2014) Density functional theory study of the concerted pyrolysis mechanism for lignin models. Energ Fuels 28: 5229-5235

77. Sano Y (1989) Reactivity of $\beta-O-4$ linkages in lignin during solvolysis pulping -Degradation of $\beta-O-4$ lignin model compounds. Mokuzai Gakkaishi 35: 813-819

78. Kishimoto T, Sano Y (2002) Delignification mechanism during high-boiling solvent pulping - Part 2. Homolysis of guaiacylglycerol- $\beta$-guaiacyl ether. Holzforschung 56:623-631

79. Li S, Lundquist K (2001) Reactions of the $\beta$-aryl ether lignin model 1-(4-hydroxy-3-methoxyphenyl)-2-(2methoxyphenoxy)-1-propanol on heating in aqueous solution. Holzforschung 55:296-301

80. Tanahashi M, Karina M, Tamabuchi K, Higuchi T (1989) Degradation mechanism of lignin accompanying steam explosions 1 . Degradation products of lignin and $\beta-O-4$ lignin substructure model dimers. Mokuzai Gakkaishi 35: 135-143

81. Ponomarev DA (1997) Formation of quinone methides: An alternative pathway of thermal degradation of some $\beta-O$ 4-ethers as compounds modeling lignin. Russ J Appl Chem 70:824-826

82. Masuku CP (1992) Thermal decomposition of coniferyl alcohol. J Anal Appl Pyrolysis 23:195-208

83. Uraki Y, Suzuki K, Ubukata M (2007) Polymerization of coniferyl alcohol by chain reaction. Another reaction for lignin formation. Cellul Chem Technol 41:505-509

84. Nakamura T, Kawamoto H, Saka S (2007) Condensation reactions of some lignin related compounds at relatively low pyrolysis temperature. J Wood Chem Technol 27:121-133

85. Kotake T, Kawamoto H, Saka S (2013) Pyrolysis reactions of coniferyl alcohol as a model of the primary structure formed during lignin pyrolysis. J Anal Appl Pyrolysis 104:573-584

86. Kotake T, Kawamoto H, Saka S (2014) Mechanisms for the formation of monomers and oligomers during the pyrolysis of a softwood lignin. J Anal Appl Pyrolysis 105:309-316

87. Kotake T, Kawamoto H, Saka S (2015) Pyrolytic formation of monomers from hardwood lignin as studied from the reactivities of the primary products. J Anal Appl Pyrolysis 113:57-64

88. Dorrestijn E, Mulder P (1999) The radical-induced decomposition of 2-methoxyphenol. J Chem Soc Perkin Trans 2:777-780

89. Vuori A (1986) Pyrolysis studies of some simple coal related aromatic methyl ethers. Fuel 65:1575-1583

90. Dorrestijn E, Epema OJ, van Scheppingen WB, Mulder P (1998) $o$-Quinone methide as a common intermediate in the pyrolysis of $o$-hydroxybenzyl alcohol, chroman and 1,4-benzodioxin. J Chem Soc Perkin Trans 2:1173-1178

91. Dorrestijn E, Pugin R, Nogales MVC, Mulder P (1997) Thermal decomposition of chroman. Reactivity of $o$-quinone methide. J Org Chem 62:4804-4810

92. Asmadi M, Kawamoto H, Saka S (2011) Thermal reactions of guaiacol and syringol as lignin model aromatic nuclei. J Anal Appl Pyrolysis 92:88-98
93. Asmadi M, Kawamoto H, Saka S (2012) The effects of combining guaiacol and syringol on their pyrolysis. Holzforschung 66:323-330

94. Hosoya T, Kawamoto H, Saka S (2009) Solid/liquid- and vaporphase interactions between cellulose- and lignin-derived pyrolysis products. J Anal Appl Pyrolysis 85:237-246

95. Hosoya T, Kawamoto H, Saka S (2009) Role of methoxyl group in char formation from lignin-related compounds. J Anal Appl Pyrolysis 84:79-83

96. Asmadi M, Kawamoto H, Saka S (2011) Thermal reactivities of catechols/pyrogallols and cresols/xylenols as lignin pyrolysis intermediates. J Anal Appl Pyrolysis 92:76-87

97. Zhou H, Wu C, Onwudili JA, Meng A, Zhang Y, Williams PT (2014) Polycyclic aromatic hydrocarbon formation from the pyrolysis/gasification of lignin at different reaction conditions. Energ Fuels 28: 6371-6379

98. Ledesma EB, Campos C, Cranmer DJ, Foytik BL, Ton MN, Dixon EA, Chirino C, Batamo S, Roy P (2013) Vapor-phase cracking of eugenol: distribution of tar products as function of temperature and residence time. Energy Fuels 27: 868-878

99. Ledesma EB, Mullery AA, Vu MJ, Hoang JN (2015) Lumped kinetics for biomass tar cracking using 4-propylguaiacol as a model compound. Ind Eng Chem Res 54:5613-5623

100. Wornat MJ, Ledesma EB, Marsh ND (2001) Polycyclic aromatic hydrocarbons from the pyrolysis of catechol (orthodihydroxybenzene), a model fuel representative of entities in tobacco, coal, and lignin. Fuel 80:1711-1726

101. Richter H, Howard JB (2000) Formation of polycyclic aromatic hydrocarbons and their growth to soot-a review of chemical reaction pathways. Prog Energy Combust Sci 26: 565-608

102. Frenklach M (2002) Reaction mechanism of soot formation in flames. Phys. Chem Phys 4:2028-2037

103. Ledesma EB, Marsh ND, Sandrowitz AK, Wornat MJ (2002) An experimental study on the thermal decomposition of catechol. Proc Combust Inst 29:2299-2306

104. Ledesma EB, Marsh ND, Sandrowitz AK, Wornat MJ (2002) Global kinetic rate parameters for the formation of polycyclic aromatic hydrocarbons from the pyrolyis of catechol, a model compound representative of solid fuel moieties. Energy Fuels 16: $1331-1336$

105. McMillen DF, Malhotra R, Hum GP, Chang SJ (1987) Hydrogen-transfer-promoted bond scission initiated by coal fragments. Energy Fuels 1: 193-198

106. McMillen DF, Malhotra R, Chang SJ, Ogier WC, Nigenda SE, Fleming RH (1987) Mechanisms of hydrogen transfer and bond scission of strongly bonded coal structures in donor solvent systems. Fuel 66:1611-1620

107. Jones BW, Neuworth MB (1952) Thermal cracking of alkyl phenols-mechanism of dealkylation. Ind Eng Chem 44: 2872-2876

108. Buryan P (1991) Thermal-decomposition of dimethylphenol. J Anal Appl Pyrolysis 22:83-93

109. Salmén L (2004) Micromechanical understanding of the cellwall structure. C R Biol 327:873-880

110. Kawamoto H (2016) Review of reactions and molecular mechanisms in cellulose pyrolysis. Curr Org Chem 20: 2444-2457

111. Kawamoto H, Ueno Y, Saka S (2013) Thermal reactivities of non-reducing sugars in polyether-role of intermolecular hydrogen bonding in pyrolysis. J Anal Appl Pyrolysis 103:287-292

112. Kawamoto H, Hosoya T, Ueno Y, Shoji T, Saka S (2014) Thermal stabilization and decomposition of simple glycosides in the presence of aromatic substances in closed ampoules: the role of $\mathrm{OH}-\pi$ hydrogen bonding. J Anal Appl Pyrolysis 109:41-46

113. Kawamoto H, Watanabe T, Saka S (2015) Strong interactions during lignin pyrolysis in wood-a study by in situ probing of 
the radical chain reactions using model dimers. J Anal Appl Pyrolysis 113:630-637

114. Hosoya T, Kawamoto H, Saka S (2008) Different pyrolytic pathways of levoglucosan in vapor- and liquid/solid-phases. J Anal Appl Pyrolysis 83:64-70

115. Fukutome A, Kawamoto H, Saka S (2015) Processes forming gas, tar, and coke in cellulose gasification from gas-phase reactions of levoglucosan as intermediate. ChemSusChem 8:2240-2249
116. Hosoya T, Kawamoto H, Saka S (2006) Thermal stabilization of levoglucosan in aromatic substances. Carbohydr Res 341:2293-2297

117. Hosoya T, Kawamoto H, Saka S (2007) Cellulose-hemicellulose and cellulose-lignin interactions in wood pyrolysis at gasification temperature. J Anal Appl Pyrolysis 80:118-125 